Synthesis (Stuttg). 2018 January ; 50(2): 278-281. doi:10.1055/s-0036-1588580.

\title{
Scalable Synthesis of Hydrido-Disiloxanes from Silanes: A One- Pot Preparation of 1,3-Diphenyldisiloxane from Phenylsilane
}

\author{
Joseph A. Buonomo, Carter G. Eiden, and Courtney C. Aldrich \\ University of Minnesota, Department of Medicinal Chemistry, Weaver-Densford Hall, 308 Harvard \\ St. SE Minneapolis, MN 55455, USA
}

\begin{abstract}
A simple, one-pot, and high-yielding synthesis of 1,3-diphenyldisiloxane is presented. The preparation of similar symmetrical disiloxane materials is also accomplished with this same protocol. This mechano-chemical procedure is efficient and highly scalable, furnishing a convenient route to hydrido-disiloxanes from widely accessible commercially available silanes.
\end{abstract}

\section{Graphical abstract}

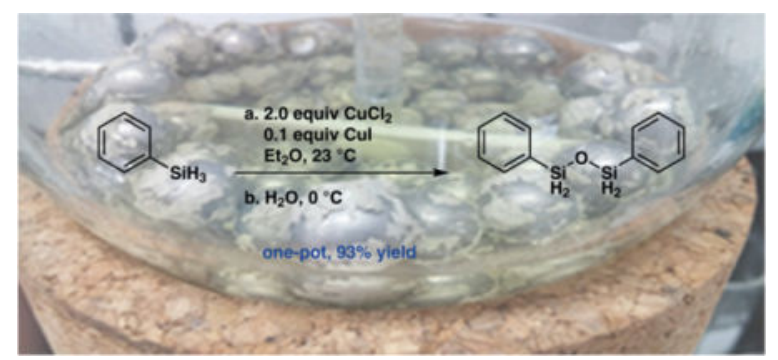

\section{Keywords}

siloxane; silane; chlorination; copper; ball-milling; one-pot

\begin{abstract}
The reduction of phosphine oxides with silanes occurs with high specificity and fidelity, and represents one of the most useful methods for the synthesis of phosphines. ${ }^{1}$ The chemoselectivity of this process also allows for in situ recycling of phosphine oxide byproducts to afford catalytic versions of the Wittig, Staudinger, and Mitsunobu reactions, among many others. ${ }^{2}$ However, silane-mediated reduction of phosphine oxides generally requires both elevated temperatures $\left(80-110^{\circ} \mathrm{C}\right)$ and additives, thereby substantially limiting the substrate scope. We recently discovered that hydridophenyl-disiloxanes facilitate reduction of phosphine oxides in a very rapid manner. ${ }^{3}$ Subsequent testing of multiple hydridophenyl-disiloxanes revealed that 1,3-di-phenyldisiloxane (DPDS) is the most reactive, promoting rapid reduction under ambient conditions. ${ }^{3}$ DPDS is a bench stable and innocuous reagent that can provide two equivalents of phenylsilanol through in situ
\end{abstract}

Supporting Information

Supporting information for this article is available online at https://doi.org/10.1055/s-0036-1588580. 
hydrolysis. We have shown that DPDS is the mildest reagent available for reduction of phosphine oxides to phosphines, combining the chemoselectivity of silanes with the low temperature capabilities of much harsher methodologies. ${ }^{1 \mathrm{~d}}$ It can be used both to prepare phosphine ligands with extremely diverse scaffolds as well as to recycle phosphine oxides in ambient catalytic phosphine redox reactions. ${ }^{3}$ Unfortunately, current methods to produce DPDS and other di- and tetra-substituted hydrido-disiloxanes from silanes are complicated by over-oxidation. These limitations hamper the usage of DPDS and prevent the investigation and development of additional hydrido-disiloxanes. We were thus prompted to develop an experimentally simple, safe, and high-yielding reaction to access this important, yet largely unexplored class of compounds (Scheme 1).

The synthesis of silanols and disiloxanes is well known as these compounds have applications in a broad range of chemistry, from the synthesis of therapeutics ${ }^{4}$ to liquid crystals. ${ }^{5}$ Transition-metal-catalyzed oxidation of precursor silanes is the most common strategy to prepare silanols and disiloxanes, ${ }^{6}$ but these methods lead to complete oxidation of the silane to either a mono-, di-, or tri-silanol depending on the number of $\mathrm{Si}-\mathrm{H}$ bonds. ${ }^{7}$

One report of an In(III)-catalyzed direct oxidation suggests that the mono-oxidation product can be obtained $;{ }^{8}$ however, this reaction was only performed on a small scale, and the reaction was not extended to phenylsilane. The generation of a full equivalent of hydrogen gas is also a safety concern. Hydrido-disiloxanes have historically been prepared through an alternative two-step sequence involving preparation and isolation of a mono-halogenated silane followed by hydrolysis (Scheme 2) ${ }^{9}$ Synthesis of the intermediate halosilanes is challenging, as is evident by the lack of their commercial availability, ${ }^{10}$ with multiple methods furnishing complex mixtures. ${ }^{11}$ Consequently, much effort has been put into the synthesis of mono-halogenated silanes, and two complimentary approaches have emerged that address previous synthetic deficiencies. The first of these employs concentrated $\mathrm{HBr}$ to displace a phenyl group on a silane with a bromide, ${ }^{12}$ while the second approach uses copper(II) chloride to directly chlorinate hydrido-silanes. ${ }^{13}$ Zhang and co-workers ${ }^{13 \mathrm{~b}}$ further improved on the latter copper(II) chloride halogenation through 'ball-milling'. Herein, we report a one-pot experimental method for the preparation of DPDS and related hydridodisiloxane reagents in high purity from commercially available silanes. This scalable procedure furnishes hydrido-disiloxanes in improved yield, ${ }^{9,13}$ and substantially lowers the time required to obtain product with only a single purification step.

The synthesis of DPDS begins with the complexation of $\mathrm{CuCl}_{2}$ and catalytic $\mathrm{CuI}$ in diethyl ether for $30 \mathrm{~min}$ in the presence of either chrome or ceramic spheres. Phenylsilane is then added and the reaction is ball-milled at $350 \mathrm{rpm}$ at ambient temperature under air with an overhead stirrer for $1.5 \mathrm{~h}$ until $100 \%$ conversion is noted by ${ }^{1} \mathrm{H}$ NMR analysis to afford the intermediate chlorophenylsilane. The reaction mixture is filtered directly onto ice chips (Figure S1, Supporting Information) and extracted with diethyl ether to afford DPDS in 93\% percent yield and approximately 95\% purity, which is sufficient for most applications. Distillation under high vacuum can be performed to provide DPDS in $>99 \%$ purity and $88 \%$ overall yield when higher purity is required (Table 1, entry 1). The reaction is scalable and does not require increased reaction times to obtain purified product. For example, DPDS is obtained in $88 \%$ yield on a 10 gram scale in less than three hours. The reaction conditions can be extended to secondary arylsilanes as well as alkyl-silanes, as diphenylsilane and $n$ - 
hexylsilane were readily converted into 1,1,3,3-tetraphenyldisiloxane $\mathbf{2 b}$ and 1,3-di- $\boldsymbol{n}$ hexyldisiloxane $2 \mathbf{c}$ in $90 \%$ and $85 \%$ yield, respectively (entries 2 and 3), and a combination of these substitution patterns was also tolerated as 1,3-dimethyl-1,3-diphenyldisiloxane 2d was synthesized in $85 \%$ yield (entry 4 ).

Our efficient approach utilizes mechano-chemistry in an effort to significantly reduce the reaction time from more than 8 hours (magnetic stirring) to only 1.5 hours. During the reaction, $\mathrm{CuCl}_{2}$ is reduced to a $\mathrm{Cu}(\mathrm{I})$ species, which coats the $\mathrm{CuCl}_{2}$ particles and hinders progression of the reaction. The physical grinding during the comminution process ensures $\mathrm{CuCl}_{2}$ is continually exposed. As such, the balls utilized should be fairly large in diameter (at least $1 / 2$ inch) to avoid the inhibition of the reaction through buildup of byproduct on the heterogeneous $\mathrm{CuCl}_{2}$. We explored different materials for the ball-milling procedure and found ceramic spheres were preferred over chrome spheres since the reaction yield was compromised when metal balls were reused multiple times (Table S1, Supporting Information). This is likely due to the inert nature of ceramic, as this material is chemically stable to the reaction conditions. Another advantage with respect to laboratory scale reactions utilizing transition-metal catalysis is that the $\mathrm{CuCl}_{2}$-mediated mechano-chemical method does not produce a stoichiometric amount of hydrogen gas, and all byproducts are simply washed away with cold water. In addition, this protocol can be implemented in standard laboratory glassware, rather than requiring specialized ball-milling equipment.

We have described an efficient one-pot, mechano-chemical procedure for the synthesis of hydrido-disiloxanes. The high yield, simple experimental set-up, and short reaction time are all ideal for laboratory scale preparations of hydrido-disiloxanes, which are valuable compounds for the chemoselective reduction of phosphine oxides. The ability to easily prepare useful quantities of hydrido-disiloxanes is expected to not only make the newly characterized reducing agent DPDS highly accessible for both phosphorous recycling and phosphine synthesis, but also to unleash the full potential of this entire class of underexplored reagents through stimulating further investigations into their unique reactivity.

$\mathrm{CuCl}_{2}$ was purchased from Strem and used as received. Phenylsilane and diphenylsilane were purchased from Oakwood Chemical and used as received. CuI, hexylsilane, methyl(phenyl)silane, and diethyl ether were purchased from SigmaAldrich and used as received. All reagents were stored in a light-shielding dessicator. All reactions at $15 \mathrm{mmol}$ or larger scale were performed using the mechano-chemical procedure employing degreased balls from VXB.com (see the Supporting Information) and an IKA RW-16-Basic overhead stirring apparatus. NMR spectra were recorded with a Bruker Avance $500 \mathrm{MHz}$ spectrometer operating at $500 \mathrm{MHz}$ for ${ }^{1} \mathrm{H}$ signals and $126 \mathrm{MHz}$ for ${ }^{13} \mathrm{C}$ signals. NMR chemical shifts are reported in ppm in reference to the residual solvent peak $\mathrm{CDCl}_{3}(\delta=7.26$ ppm for ${ }^{1} \mathrm{H}$ and $\delta=77.1 \mathrm{ppm}$ for ${ }^{13} \mathrm{C}$ ) as an internal standard. 


\section{1,3-Diphenyldisiloxane [17962-59-3] (2a);9a Typical Procedure}

On the benchtop, under air, a two-necked $500 \mathrm{~mL}$ round-bottom flask equipped with thirtyfive 5 inch diameter balls, was charged with $\mathrm{CuCl}_{2}$ (12.1 g, 90 mmol, 2.0 equiv), $\mathrm{CuI}$ (857 $\mathrm{mg}, 4.5 \mathrm{mmol}, 0.1$ equiv), and $\mathrm{Et}_{2} \mathrm{O}(60 \mathrm{~mL})$. An overhead stirrer with a flat paddle was fitted to the reaction vessel and the mixture was stirred at $30 \%$ speed (ca. $350 \mathrm{rpm}$ ) for 30 min. The stirrer was stopped and phenylsilane $(5.54 \mathrm{~mL}, 45 \mathrm{mmol}, 1.0$ equiv) was added down the walls of the flask; a color change was noted immediately (see photographs in the Supporting Information). Stirring at 30\% speed was resumed and allowed to proceed for the duration of the reaction. The progress of the reaction was easily monitored by ${ }^{1} \mathrm{H}$ NMR spectroscopic analysis. Upon completion, the reaction mixture was filtered through a Büchner funnel directly onto ice ( $45 \mathrm{~g}, 2.5 \mathrm{~mol})$ to remove copper salts and the balls, and the cake was washed with additional $\mathrm{Et}_{2} \mathrm{O}(30 \mathrm{~mL})$. The mixture was swirled by hand every 5 min until the ice melted (15-45 min). The layers were separated and the organic layer was washed with cold de-ionized water $(2 \times 60 \mathrm{~mL})$. The organic layer was then dried with $\mathrm{MgSO}_{4}$ and evaporated at $40{ }^{\circ} \mathrm{C}$ at reduced pressure (22 Torr) to remove trace unreacted phenylsilane. The title compound 2a was obtained as a colorless to pale-yellow oil (4.80 g, $20.9 \mathrm{mmol}$ ) in $93 \%$ yield. The material was approximately $95 \%$ pure by ${ }^{1} \mathrm{H}$ NMR analysis. If necessary, the product can be further purified by distillation at reduced pressure (bp $76{ }^{\circ} \mathrm{C}$ at 580 mTorr; Lit..$^{9 a}$ bp $85^{\circ} \mathrm{C}$ at 800 mTorr). After distillation, a colorless oil was obtained $(4.55 \mathrm{~g}, 19.8 \mathrm{mmol}, 88 \%$ yield). Analytical data reported below is for material that was not additionally distilled.

${ }^{1} \mathrm{H} \mathrm{NMR}\left(\mathrm{CDCl}_{3}, 500 \mathrm{MHz}\right): \delta=7.53(\mathrm{~d}, J=7.6 \mathrm{~Hz}, 4 \mathrm{H}), 7.37(\mathrm{t}, J=7.6 \mathrm{~Hz}, 2 \mathrm{H}), 7.32(\mathrm{t}$, $J=7.2 \mathrm{~Hz}, 4 \mathrm{H}), 5.06(\mathrm{~s}, 4 \mathrm{H})$.

${ }^{13} \mathrm{C} \mathrm{NMR}\left(\mathrm{CDCl}_{3}, 126 \mathrm{MHz}\right): \delta=134.10,130.54,128.13$.

HRMS (ESI): $\mathrm{m} / z$ [M + Na] calcd for $\mathrm{C}_{12} \mathrm{H}_{14} \mathrm{NaOSi}_{2}$ : 253.0475; found: 253.0471 .

\section{1,1,3,3-Tetraphenyldisiloxane (2b) $)^{14,15}$}

[CAS Reg. No. 15545-80-9]

The procedure for $2 \mathbf{a}$ was followed on $15.0 \mathrm{mmol}$ scale using ten 5 inch diameter balls. The title compound $\mathbf{2 b}$ was obtained.

Yield: $2.58 \mathrm{~g}$ (6.75 mmol, 90\%); colorless/white solid; mp 48-49 ${ }^{\circ} \mathrm{C}$ [Lit. ${ }^{15} \mathrm{mp} .46-49{ }^{\circ} \mathrm{C}$ (ethanol)].

${ }^{1} \mathrm{H} \mathrm{NMR}\left(\mathrm{CDCl}_{3}, 500 \mathrm{MHz}\right): \delta=7.48(\mathrm{~d}, J=6.9 \mathrm{~Hz}, 8 \mathrm{H}), 7.34(\mathrm{t}, J=7.4 \mathrm{~Hz}, 4 \mathrm{H}), 7.27$ (t, $J=7.7 \mathrm{~Hz}, 8 \mathrm{H}), 5.52(\mathrm{~s}, 2 \mathrm{H})$.

${ }^{13} \mathrm{C} \mathrm{NMR}\left(\mathrm{CDCl}_{3}, 126 \mathrm{MHz}\right): \delta=134.33,130.24,127.96$.

HRMS (ESI): $m / z[M+\mathrm{H}]$ calcd $\mathrm{C}_{24} \mathrm{H}_{23} \mathrm{OSi}_{2}$ : 383.1282; found: 383.1280 . 


\section{1,3,-Di-n-hexyldisiloxane (2c) ${ }^{8}$}

[CAS Reg. No. 1203611-82-8]

The procedure for $\mathbf{2 a}$ was followed on $15.0 \mathrm{mmol}$ scale using ten 5 inch diameter balls. Additional purification of this product, if needed, was achieved by distillation at reduced pressure (bp $76{ }^{\circ} \mathrm{C}$ at 580 mTorr) to give the title compound $\mathbf{2 c}$.

Yield: $1.57 \mathrm{~g}(6.38 \mathrm{mmol}, 85 \%)$; colorless to pale-yellow oil.

${ }^{1} \mathrm{H} \mathrm{NMR}\left(\mathrm{CDCl}_{3}, 500 \mathrm{MHz}\right): \delta=4.52(\mathrm{t}, J=2.6 \mathrm{~Hz}, 4 \mathrm{H}), 1.36-1.22(\mathrm{~m}, 20 \mathrm{H}), 0.82(\mathrm{t}, J=$ $6.9 \mathrm{~Hz}, 6 \mathrm{H})$.

${ }^{13} \mathrm{C}$ NMR $\left(\mathrm{CDCl}_{3}, 126 \mathrm{MHz}\right): \delta=32.34,31.55,22.92,22.54,14.47,14.10$.

HRMS (ESI): $m / z$ [M + Na] calcd $\mathrm{C}_{12} \mathrm{H}_{30} \mathrm{NaOSi}_{2}: 269.1727$; found: 269.1732 .

\section{1,3-Dimethyl-1,3,-diphenyldisiloxane (2d) ${ }^{16}$}

[CAS Reg. No. 1203611-82-8]

The procedure for $\mathbf{2 a}$ was followed on $15.0 \mathrm{mmol}$ scale using ten 5 inch diameter balls. Additional purification of this product, if needed, was achieved by distillation at reduced pressure (bp $102{ }^{\circ} \mathrm{C}$ at 800 mTorr; Lit. ${ }^{16 \mathrm{~b}}$ bp $105^{\circ} \mathrm{C}$ at 1 Torr) to give the title compound $\mathbf{2 d}$.

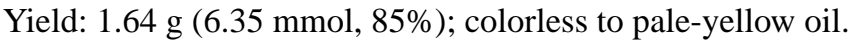

${ }^{1} \mathrm{H}$ NMR $\left(\mathrm{CDCl}_{3}, 500 \mathrm{MHz}\right): \delta=7.40(\mathrm{dt}, J=7.9,1.4 \mathrm{~Hz}, 4 \mathrm{H}), 7.25-7.19(\mathrm{~m}, 6 \mathrm{H}), 4.98$ $(\mathrm{dd}, J=2.9,1.1 \mathrm{~Hz}, 2 \mathrm{H}), 0.27(\mathrm{~d}, J=3.1 \mathrm{~Hz}, 6 \mathrm{H})$.

${ }^{13} \mathrm{C} \mathrm{NMR}\left(\mathrm{CDCl}_{3}, 126 \mathrm{MHz}\right): \delta=137.75,134.04,130.55,128.55,0.00 . \mathrm{HRMS}(\mathrm{ESI}): \mathrm{m} / \mathrm{z}$ $[\mathrm{M}+\mathrm{Na}]$ calcd $\mathrm{C}_{14} \mathrm{H}_{18} \mathrm{NaOSi}_{2}$ : 281.0788; found: 281.0799.

\section{Supplementary Material}

Refer to Web version on PubMed Central for supplementary material.

\section{Acknowledgments}

This work was supported by the University of Minnesota College of Pharmacy, an NSF Graduate Research Fellowship to J.A.B. (GRFP: 00039202), a Bighley Fellowship to J.A.B. (UMN-COP), and a Chemical-Biology Interface Training Grant to C.G.E. (T32-GM008700).

\section{References}

1. (a) Fritzsche H, Hasserodt U, Korte F, Friese G, Adrian K. Chem Ber. 1965; 98:171.(b) Horner L, Balzer WD. Tetrahedron Lett. 1965:1157.(c) Marsi KL. J Org Chem. 1974; 39:265.(d) Hérault D, Nguyen DH, Nuel D, Buono G. Chem Soc Rev. 2015; 44:2508. [PubMed: 25714261]

2. (a) O'Brien CJ, Tellez JL, Nixon ZS, Kang LJ, Carter AL, Kunkel SR, Przeworski KC, Chass GA. Angew Chem Int Ed. 2009; 48:6836.(b) van Kalkeren HA, te Grotenhuis C, Haasjes FS, Hommersom CRA, Rutjes FPJT, van Delft FL. Eur J Org Chem. 2013:7059.(c) van Kalkeren HA, Leenders SHAM, Hommersom CRA, Rutjes FPJT, van Delft FL. Chem Eur J. 2011; 17:11290. 
[PubMed: 21882274] (d) Zhao W, Yan PK, Radosevich AT. J Am Chem Soc. 2015; 137:616. [PubMed: 25564133] (e) Buonomo JA, Aldrich CC. Angew Chem Int Ed. 2015; 54:13041.

3. Buonomo JA, Eiden CG, Aldrich CC. Chem Eur J. 2017; doi: 10.1002/chem.201703875(b) Buonomo, J. A.; Cole, M.; Aldrich, C. C. unpublished results.

4. (a) Tse FLS, Chang T, Finkelstein B, Ballard F, Jaffe JM. J Pharm Sci. 1984; 73:1599. [PubMed: 6520762] (b) LeVier, RR., Chandler, ML., Wendel, SR. The Biochemistry of Silicon and Related Problems. Bendz, G., Lindqvist, I., editors. Vol. 473. Plenum Press; New York and London: 1978.

5. Imrie CT, Henderson PA. Chem Soc Rev. 2007; 36:2096. [PubMed: 17982523]

6. (a) Lee M, Ko S, Chang S. J Am Chem Soc. 2000; 122:12011.(b) Kikukawa Y, Kuroda Y, Ymamguchi K, Mizuno N. Angew Chem Int Ed. 2012; 51:2434.(c) Shimizu K, Kubo T, Satsuma A. Chem Eur J. 2012; 18:2226. [PubMed: 22278968] (d) Krüger A, Albrecht M. Chem Eur J. 2012; 18:652. [PubMed: 22162081] (e) Sawama Y, Masuda M, Yasakawa N, Nakatani R, Nishimura S, Shibata K, Yamada T, Monguchi Y, Suzuka H, Takagi Y, Sajiki H. J Org Chem. 2016; 81:4190. [PubMed: 27129497]

7. (a) Lee Y, Seomoon D, Kim S, Han H, Chang S, Lee PH. J Org Chem. 2004; 69:1741. [PubMed: 14987039] (b) Ison EA, Corbin RA, Abu-Omar MM. J Am Chem Soc. 2005; 127:11938. [PubMed: 16117522] (c) Matsuo T, Kawaguchi H. J Am Chem Soc. 2006; 128:12362. [PubMed: 16984155] (d) Mitsudome T, Arita S, Mori H, Mizugaki T, Jitsukawa K, Kaneda K. Angew Chem Int Ed. 2008; 47:7938.(e) Chauhan BPS, Sarkar A, Chauhan M, Roka A. Appl Organomet Chem. 2009; 23:385. (f) John J, Gravel E, Hagége A, Li H, Gacoin T, Doris E. Angew Chem Int Ed. 2011; 50:7533.

8. Sridhar M, Ramanaiah BC, Narsaiah C, Swamy MK, Mahesh B, Reddy MKK. Tetrahedron Lett. 2009; 50:7166.

9. (a) Mitzel NW, Shier A, Beruda H, Schmidbaur H. Chem Ber. 1992; 125:1053.(b) Harvey MC, Nebergall WH, Peake JS. J Am Chem Soc. 1957; 79:1437.

10. (10) Reagents were searched for commercial availability using the eMolecules database, and general supplier websites. The presence of available hydrido-chlorosilanes was investigated with a range of suppliers including: Sigma-Aldrich, Alfa-Aesar, Thermo-Fischer (includes multiple companies), Combi-Blocks, Oakwood Chemicals, Gelest Inc, Strem Inc, TCI chemicals, and Matrix Scientific.

11. (a) Patzold U, Roewer G, Herzog U. J Organomet Chem. 1996; 508:147.(b) Binder J, Fisher RC, Flock M, Sammler HG, Torvisco A, Uhlig F. Phosphorus, Sulfur Silicon Relat Elem. 2016; 191:478.

12. (a) Hager R, Steigelmann O, Muller G, Schmidbaur H. Chem Ber. 1989; 122:2115.(b) Schmidbaur H, Zech J, Rankin DWH, Robertson HE. Chem Ber. 1991; 124:1953.

13. (a) Kunai A, Ohshita J. J Organomet Chem. 2003; 686:3.(b) Wang W, Tan Y, He Z, Zhang Z. J Organomet Chem. 2014; 769:29.

14. Hayashi K, Iyoda J, Shiihara I. J Organomet Chem. 1967; 10:81.

15. Uvarov VM, deVekki DA, Reshetilovskii VP, Skrortsov NK. Russ J Gen Chem. 2010; 80:35.

16. (a) Benouargha A, Boulahia D, Bouterin G, Caporiccio G, Guida-Pietrasanta F, Ratsimihety A. Phosphorus, Sulfur Silicon Relat Elem. 1996; 113:79.(b) Becker B, Herman A, Wojnowski W. J Organomet Chem. 1980; 193:293. 

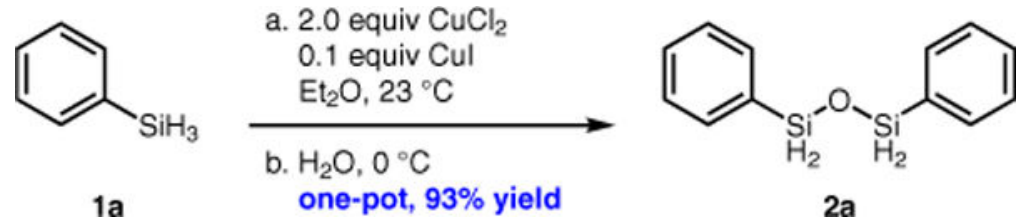

Scheme 1.

Convenient and scalable synthesis of 1,3-diphenyldisiloxane (2a) 
Previous Methods: Two purifications necessary

2

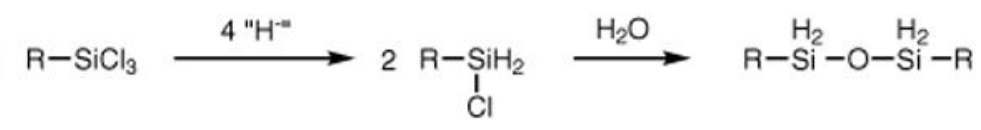

2

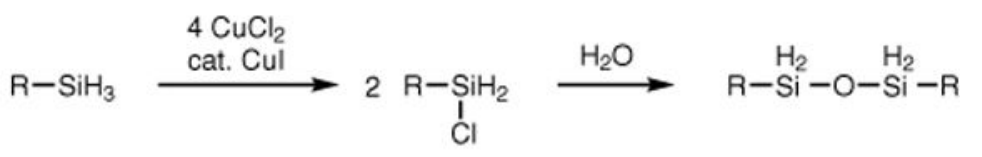

This Work: Only one purifcation

$2 \mathrm{R}-\mathrm{SiH}_{3} \stackrel{\substack{\text { a. } 4 \mathrm{CuCl}_{2} \\ \text { cat. } \mathrm{Cul}}}{\text { b. } \mathrm{H}_{2} \mathrm{O}} \mathrm{R}-\mathrm{Si}-\mathrm{O}-\mathrm{Si}-\mathrm{R}$

Scheme 2.

Synthesis of hydrido-disiloxane materials from literature and this work 


\section{Table 1}

Direct Synthesis of Symmetrical Disiloxanes from Commercially Available Silanes

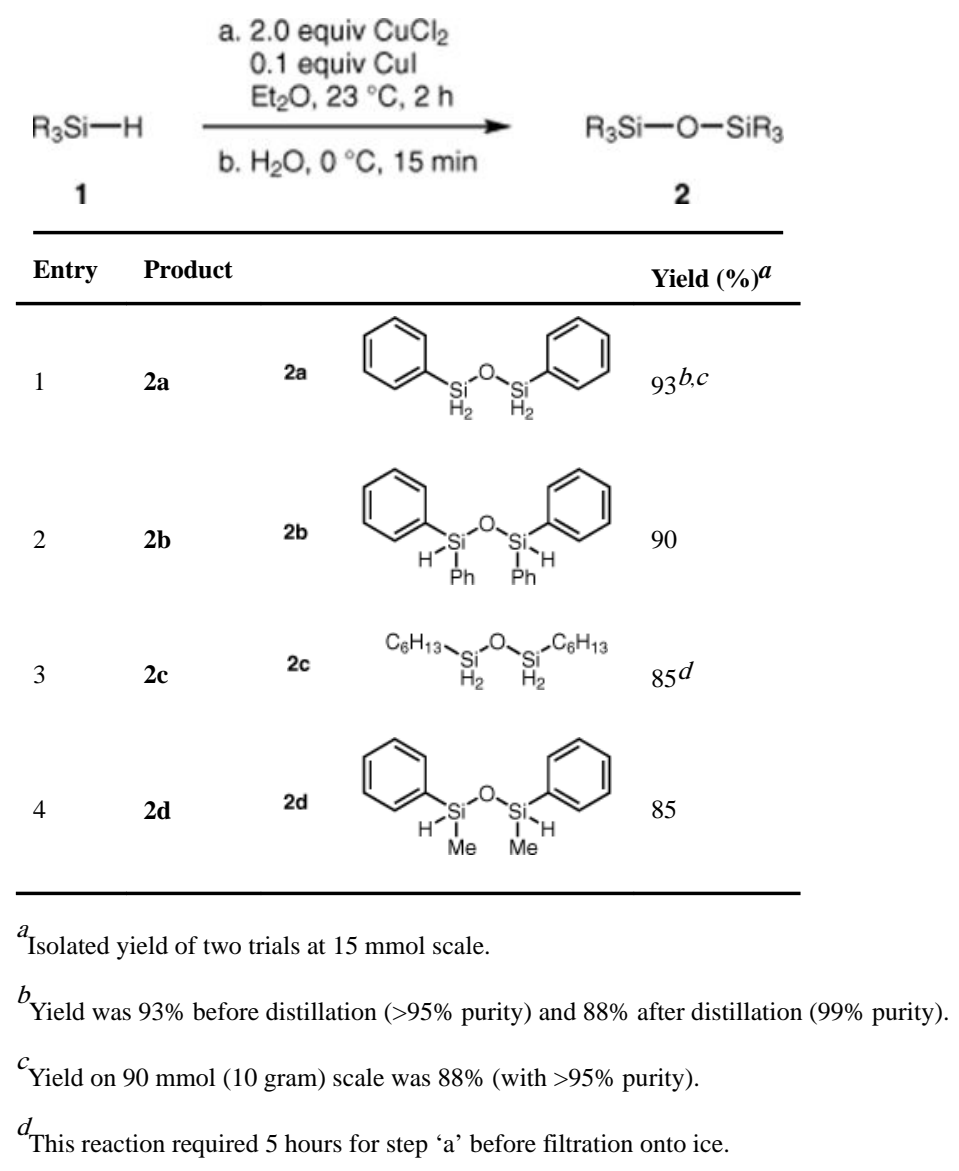

Synthesis (Stuttg). Author manuscript; available in PMC 2019 January 01. 